\title{
Medio ambiente, manipulación política y control mediático del riesgo. Análisis del caso del hundimiento del petrolero Prestige
}

\author{
Dr. Carlos Elías (carlos.elias@uc3m.es) \\ Universidad Carlos III de Madrid
}

\begin{abstract}
Resumen
El hundimiento del petrolero Prestige en las costas gallegas en 2002 ha sido uno de los peores episodios de contaminación medioambiental en España, junto con Doñana. Pero el caso Prestige también es importante desde el punto de vista mediático y científico porque ha sido la primera vez en la historia de la ciencia española en la que los científicos se unieron para luchar contra el control político del conocimiento y solicitaron auxilio a través de la revista Science. Es un caso muy interesante de la unión de intereses políticos, riesgo medioambiental y control del conocimiento científico a través de los medios de comunicación. Resulta muy complejo comparar todo esto $y$, por ello, en este artículo se ha tratado de realizar un análisis de contenido y dar una versión de los hechos desde el punto de vista del conflicto ciencia-medios de comunicación-control político. En primer lugar, se hará una cronología de los hechos, porque puede que el caso ya quede lejano. Después, se analizará la estrategia mediática y los efectos tanto políticos como científicos que tuvo.
\end{abstract}

\begin{abstract}
The oil tanker Prestige sank off the northwest coast of Spain with almost 80,000 tons oil in 2002. This has been not only of the worst episodes of environmental contamination in Spain (with Doñana) but also is important because has been the first time that in the Spanish history of science scientists joined to fight against the political control of the knowledge. Even they requested their protest in journal Science. So Prestige it is a very interesting case in which political interests, environmental risk and scientific knowledge are in competition. Results will very complicated to compare. Because of that, in this article we try to carry out a content analysis and give an explanation of the facts since the point of view of political control versus mass media and science conflicts. First of all we show a chronology, because maybe not many people remember the case. Secondly we describe the media strategy and after that will be analyzed it in order to find its political and scientific effects.
\end{abstract}

Palabras clave: Medio ambiente, Prestige, riesgo, periodismo científico.

Key words: Environment, Prestige, risk, scientific journalism. 
Medio ambiente, manipulación política y control mediático del riesgo...

\section{INTRODUCCIÓN. LOS INICIOS DEL PRESTIGE. NOVIEMBRE DE 2002}

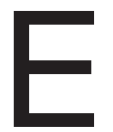

ra muy difícil, pero que muy difícil, superar el desastre de Doñana. Pero el

Prestige y su vertido son ya, con creces, la mayor catástrofe ambiental, social y económica de la Historia de España", escribió en El Mundo (28-112002: suplemento especial) el periodista especializado en Medio Ambiente Gustavo Catalán Deus. Para comparar ambas tragedias ambientales, recordaremos que el vertido de Aznalcóllar fueron cinco millones de toneladas de lodos y aguas tóxicas que se depositaron en el Parque Natural tras reventarse una balsa de decantación de las minas. La destrucción afectó a 70 kilómetros del cauce y riberas del río Guadiamar. Contaminó las huertas ribereñas, el agua y los acuíferos con metales pesados que permanecerán cientos de años en el ecosistema. También causó una mortandad masiva en la flora y la fauna del Parque Nacional. A finales de 2002, cuando ocurrió la tragedia ecológica del Prestige, se llevaban gastados en la rehabilitación de Doñana entre 216 y 300 millones de euros, según fuentes del Ministerio de Medio Ambiente. Ese año aún no estaba, ni de lejos, descontaminado el entrono Doñana, pero aquella tragedia ya apenas aparecía en los medios de comunicación.

El petrolero Prestige empezó a ser noticia el 13 de noviembre de 2002 cuando se conoció que había un carguero a la deriva cerca de las costas gallegas. Las consecuencias de la catástrofe fueron obvias para todos: 1.000 kilómetros de costa gallega y cantábrica afectada por el vertido de, según se dijo en un principio, "sólo 4.000 toneladas de crudo". Comparadas con las 20.000 toneladas que el petrolero Erika derramó a 400 kilómetros de las costas francesas en 1999 o, sobre todo, con las 38.000 toneladas que vertió en 1989 el Exxon Valdez en las costas de Alaska, esas 4.000 toneladas del Prestige no parecía mucho.

Pero en esos momentos se obviaron dos datos importantes. El Prestige estaba a la deriva y podía hundirse -como de hecho sucedió- y aún almacenaba unas 60.000 toneladas de fuel en sus bodegas. Por ello era tan importante averiguar si existían grietas -algo que todo el mundo suponía-, el alcance de las grietas así como el flujo que salía por ellas. De hecho, tan sólo un mes después del hundimiento ya se calculaba que habían salido unas 17.000 toneladas de fuel.

El segundo dato importante que se obvió en esos primeros días fue el tipo de fuel que llevaba el petrolero. Fue curioso observar cómo en los primeros días las autoridades, tanto científicas como políticas, insistían a los periodistas en que usaran el término fuel, en lugar de petróleo o crudo. Cuenta el periodista Gustavo Catalán Deus que "el término fuel parecía menos dañino que petróleo o crudo y las autoridades precisaban mucho el adjetivo "(El Mundo, 28-11-2002)". Pero lo que llevaba el Prestige era "fuel del tipo número 6", en la terminología inglesa. Es decir, el peor de todos porque es viscoso -con lo que cuesta eliminarlo- y, además, tenía sustancias potencialmente cancerígenas. Este fuel del Prestige se obtiene como residuo tras el refino del petróleo en el que el crudo se calienta a 400 grados en una torre de destilación. 
Para que el lector se haga una idea, de todos los componentes del petróleo, los gases del petróleo son los más volátiles y lo primero que se obtiene. Tras ellos va la gasolina, el queroseno, los gasóleos, las aceites lubricantes y, después, el fuel. Tras él sólo quedan los asfaltos. Señalo esto para que el lector compruebe la viscosidad del fuel. Es conveniente detallar esto porque el asunto de la viscosidad y las grietas fue fundamental en la estrategia de manipulación en este caso. La viscosidad se define como la resistencia que ofrece un líquido a fluir. Disminuye al aumentar la temperatura, por lo que en las frías aguas del fondo marino, alguien se aventuró a decir que como el fuel era muy viscoso no saldría por las grietas.

Otro parámetro físico-químico importante era la densidad, definida como la masa por unidad de volumen, normalmente en gramos por centímetros cúbicos. Dicho en palabras más sencillas, de la densidad depende que un material se hunda o flote. Si tomamos como medida el agua pura que tiene densidad uno, todo lo que tenga menos densidad flotará y lo que tenga más se hundirá. Por ejemplo, la gasolina, que tiene densidad 0,68, flotará en el agua. Lo mismo le sucede a la madera cuya densidad es 0,9. El fuel tiene densidad 0,96 por lo que, en principio, flotaría en el agua aunque estaría casi en el límite. No obstante, hay que matizar que el agua del mar, al ser en realidad una disolución de agua y de sal, no tiene densidad 1 sino 1,04 .

Parece una matización baladí esos 0,04 , pero no lo es. Esta diferencia de densidad es lo que permite, por ejemplo, que los iceberg -que son de agua dulce y, por tanto, tienen densidad 1- floten en el mar. Cuanto más salino sea el mar, más densidad tendrá y más cosas flotarán. Por eso si nos bañamos en el Mar Muerto tenemos la sensación de que flotamos más que en otros sitios. Viene todo esto a cuento porque no había que ser muy listo para saber que el fuel iba a flotar en un medio como el agua marina con densidad 1.04.

\section{CRONOLOGÍA DE LOS HECHOS}

Conviene precisar bien cómo fueron los hechos durante la primera semana para, después, adentrarnos en la estrategia de manipulación mediática. El caso Prestige en el momento de redactar este análisis -2005- aún seguía dando que hablar. Pero realmente todo se basa en las interpretaciones de lo que sucedió en los primeros siete días.

13-11-2002. Miércoles. El capitán del Prestige, Apostolos Mangouras, un viejo lobo de mar con más de 44 años de navegación, lanza un SOS. Su petrolero se encuentra en apuros cerca del cabo Finisterre. Los datos del petrolero son los siguientes: el armador era griego, la bandera era de Bahamas. El año de construcción era 1976. Y algo muy importante que luego tendría repercusión mediática: el tipo de casco era simple. Por esa razón, y por su antigüedad, el Prestige estaba incluido en la lista negra de las grandes petroleras del mundo catalogado como 
Medio ambiente, manipulación política y control mediático del riesgo...

"buque peligroso". Según la normativa europea vigente en 2002 los petroleros debían tener doble casco, pero al parecer sólo era aplicable a los de nueva construcción. Los dueños del Prestige también eran propietarios del Mar Egeo, un petrolero que causó la catástrofe ecológica de 1992 al encallar en La Coruña.

14-11-2002. Jueves. El Prestige, roto y aún repleto de fuel, se encuentra a la deriva a siete millas de las playas de Muxía. El capitán no colabora, y las autoridades piden que una unidad de elite de la Guardia Civil asalte el barco. La noticia ya aparece en la primera página de todos los diarios y abre los informativos.

15-11-2002. Viernes. La Guardia Civil detiene al capitán Mangouras mientras su barco sigue expulsando fuel en el último viaje. La obsesión en los despachos del gobierno es alejar el petrolero "hasta el quinto pino" (El País, 16-11-2002), lo más lejos posible de las costas gallegas. En ese momento aún no había llegado el fuel a las costas. Se llegó a decir que los helicópteros que sobrevolaron el barco no observaron que la mancha fuera muy grande. Los periodistas que fueron en esos helicópteros dijeron que la mancha sí les pareció "muy grande (El País y El Mundo, 16-11-2002)". Desde el Gobierno se matizó que "los periodistas no están acostumbrados a calibrar técnicamente manchas de petróleo desde un helicóptero". La decisión de alejar el petrolero sería en el futuro motivo de polémica, pues algunos expertos sostuvieron que hubiese sido mejor meterlo en el puerto de La Coruña y confinar allí el vertido. Alegaron también que la zona donde lo llevaron tiene corrientes marinas que empujan el vertido hacia las costas gallegas. Los expertos del gobierno rebatían estas teorías señalando que también se hubiese salido el fuel del puerto y, sobre todo, éste hubiese inutilizado el puerto durante meses o años. Criticaron que los que defendían el haber metido el petrolero en el puerto de La Coruña lo hicieron a "toro pasado", pero que el instinto de cualquier persona es alejarse del peligro ( $y$ en este caso alejar el peligro) y que les hubiese gustado saber qué hubiese pasado con la opinión pública y la oposición si se hubiese llevado el petrolero al puerto de La Coruña. El debate, como sucedió en Doñana (Elías, 2001), siguió en términos técnicos y científicos y nadie cedió en sus posiciones. El ministro de Agricultura y Pesca de entonces, Miguel Arias Cañete, señaló dos días después del hundimiento que "remolcando el barco se ha evitado un desastre ecológico de magnitudes incalculables del cual el sector pesquero gallego hubiera tardado mucho en recuperarse". Añadió que, "sin embargo, el ecosistema se recuperará en un plazo razonable".

16-11-2002. Sábado. El presidente del Gobierno de ese entonces, José María Aznar, toma cartas en el asunto cuando las primeras oleadas de fuel inundan el sábado 16 de noviembre las playas gallegas y encarga a su vicepresidente Mariano Rajoy, de origen gallego, que coordine el plan de actuación. Algunos gobernantes 
del Partido Popular se relajan y se marchan de cacería con la tranquilidad de haber alejado el petrolero de las costas gallegas.

Esas "relajaciones" fueron importantes a la hora de interpretar las reacciones de la población contra los políticos. El presidente de la Xunta gallega en ese momento, Manuel Fraga, participa en una cacería a las afueras de Madrid. Francisco Álvarez-Cascos, el ministro de Fomento y responsable último de la decisión de alejar el Prestige de Galicia estaba también de caza en los Pirineos. El ministro de Medio Ambiente, Jaume Matas, descansaba, paradójicamente, en el parque Nacional de Doñana.

Mientras que los políticos madrugan para pegar tiros, los gallegos se despiertan alarmados: el chapapote inunda y contamina ya sus costas. El presidente de Gobierno, José María Aznar, tardó un mes en viajar a Galicia aunque hubo una rápida aprobación de las ayudas. Este fue uno de los fallos de la estrategia manipuladora del PP. En un caso de crisis, los responsables políticos no pueden "irse de vacaciones" y deben declarar sobre las ayudas a tramitar "en el lugar del accidente". Mediáticamente, aunque sea desde la hipocresía, estas acciones dan muy buen resultado porque una de las formas más útiles de manipulación es apelando al sentimiento de emotividad.

17 y 18-11-2002. Domingo y Lunes. El Prestige sigue alejándose y perdiendo fuel. Es portada en todos los medios de comunicación porque ya ha llegado la marea negra a Galicia y porque se especula con que se hunda. Se crea el gabinete de crisis y, al igual que en el caso Doñana, se sugiere que la mejor opción es el CSIC. EI jefe de prensa del CSIC continúa siendo el que estaba en la época de Doñana, Javier Fernández Carvajal. Él es quien vuelve a diseñar la estrategia mediática. Desde el punto de vista de la manipulación, vuelve a ser una estrategia brillante y da idea de cómo han evolucionado las técnicas de los gabinetes de prensa.

Sin embargo, al contrario que en la catástrofe de Doñana, el presidente del CSIC en 2002 ya no era César Nombela. Ahora era Rolf Tarrach, un catedrático de Física de la Autónoma de Barcelona, catalán, afín a la ministra de Ciencia y Tecnología Anna Birulés que lo nombró y al compañero de estudios de Birulés y también ministro del PP Josep Piqué. En ese momento, Piqué había sustituido a Birulés como ministro de Ciencia y Tecnología. El clan catalán no es bien visto en el PP nacional por su excesivo progresismo. No se confía en ellos, especialmente en Tarrach (al que se considera demasiado independiente y con ideas propias), para una tarea tan delicada de manipulación y, en este caso, el presidente de la comisión científica del Prestige no será el presidente del CSIC como ocurrió en Doñana. En el Prestige el presidente del comité científico fue Emilio Lora Tamayo, vicepresidente del CSIC, también físico (aunque experto en microelectrónica) e hijo del ministro de Educación de Franco que cerró cinco universidades y usó la represión policial contra los estudiantes y profesores que pedían libertad en la dictadura. Rolf Tarrach, ante esta humillación y falta de confianza, dimitirá dos 
meses después del nombramiento de Lora Tamayo como presidente del comité de crisis del CSIC. Lora Tamayo también le sustituirá como presidente del CSIC. Haber aceptado ser el presidente del comité del Prestige, puenteando a su entonces jefe, tenía su recompensa. Esta circunstancia y, sobre todo, el hecho de que el PP tenía una mayoría absoluta (algo que no ocurría en 1998) propició que la campaña de manipulación mediática del CSIC en este caso fuera tan descarada que, por primera vez en España, como veremos más adelante, la comunidad científica se rebeló antes estas formas.

Desde el punto de vista político el ministro de Agricultura y Pesca, Miguel Arias Cañete, uno de los primeros en visitar la zona, señaló el día 17: "Aquí no hay marea negra ni riesgo de contaminación". Y todos los medios recogieron sus declaraciones. Unas horas después de la declaración eran desmentidas por la naturaleza.

19-11-2002. Martes. Los abogados del capitán Mangouras piden que se remitan al juzgado de Corcubión las cintas, íntegras y sin limpiar, de las conversaciones entre la torre de control, los remolcadores y el petrolero. El Prestige se hunde partido en dos. La imagen da la vuelta al mundo. Hay que comenzar la estrategia de manipulación mediática y ese mismo día se pone en marcha.

\section{ESTRATEGIA DE COMUNICACIÓN}

El día 19 noviembre, cuando el Prestige se hunde "quince minutos antes del mediodía" -según los medios de comunicación- lo hace primero por su popa. Por tanto a esa hora estalla la crisis en el CSIC. Se sabe que eso abrirá todos los informativos del mediodía. La proa quedará flotando hasta las cuatro de la tarde. Cuando también se hunde, las cadenas de radio y televisión y las ediciones digitales de los periódicos dan el avance. La noticia es un bombazo informativo de primera magnitud en todo el mundo. La noticia no puede pararse, pero debe matizarse su impacto, esa será la estrategia. Debe aclararse que la estrategia será muy parecida a la de Doñana en 1998 (Elías, 2001). La única diferencia es que en el Prestige se tarda más tiempo (26 días) en nombrar al comité científico asesor.

\section{PRIMER PASO. IDEAS POSITIVAS Y ESPECULACIÓN CIENTÍFICA AFÍN AL GOBIERNO}

La misma tarde del hundimiento un científico del CSIC, José Luis García Fierro, del Instituto de Catálisis y Petroleoquímica, ofrece unas declaraciones a las agencias que, el día siguiente, recogió toda la prensa nacional. A juicio de García Fierro, el hundimiento del barco es una buena noticia -idea positiva- porque dejará de verter fuel. En su opinión, la presión del agua -el barco se depositó a 3.600 metros de profundidad- y las bajas temperaturas -en torno a 2,4ํㅡ C- convertirán el fuel "en una sustancia sólida difícil de moverse y dispersarse". Es decir, que se 
había acabado el problema. Esta fue la tesis que manejó el gobierno durante esos días y que apareció en boca de algunos ministros. De hecho, el delegado del Gobierno en Galicia, Arsenio Fernández de Mesa, llegó a decir el mismo día 19 que "el fuel se ha convertido en un ladrillo en el fondo del mar", apoyándose en los "estudios de García Fierro".

Sin embargo, García Fierro sólo opinaba. No había estudios científicos que avalaran esa hipótesis aunque él hablaba como si existieran. Los periodistas también le creyeron y la tensión pareció relajarse. Sin embargo, la prensa francesa (Le Monde y Liberation, 20-11-2002) criticaron duramente la postura científica española: "Todavía hay petroleros hundidos durante la Segunda Guerra Mundial que contaminan los mares", dijeron los experto franceses. Ese día 20, cuando se leyó la prensa francesa en España un investigador del Instituto Español de Oceanografía, que también pertenece al Gobierno, matizó las declaraciones de García Fierro: "El fuel tardará años en degradarse. Además, existen muy pocas investigaciones que puedan confirmar que a más de 3.000 metros estos materiales se solidifican". La polémica científica estaba servida y cada político buscaba el científico que mejor defendiera sus intereses. Pero las ciencias naturales, al contrario que las ciencias sociales, tienen una ventaja: sus resultados pueden comprobarse fácilmente. Y el fuel siguió saliendo por las grietas hasta que éstas se taponaron. El 13 de diciembre de 2002 (casi un mes después del hundimiento, el batíscafo francés Nautile logra sellar la primera grieta (la noticia es portada en toda la prensa del día siguiente). Pues bien: desde el hundimiento hasta el sellado de esa grieta salieron del Prestige unas 15.000 toneladas más, desmintiendo así la teoría de García Fierro.

\section{SEGUNDO PASO: LOS INFORMES}

En toda estrategia de manipulación que se precie es preciso "dar de comer" a los periodistas información sesgada o manipulada o encriptada, o las tres cosas al mismo tiempo. Como sucedió en Doñana (Elías, 2001), en el momento de máximo furor de la crisis informativa, el número de informes debe ser mayor. Toda esta estrategia se realiza a través de informes elaborados por ingenieros o científicos de la administración (técnicos) que, por supuesto, harán dos tipos de informes. Unos reales, que le darán a los responsables y sus jefes directos, y otros que son los que emiten a la prensa. Otras veces son los propios periodistas de los gabinetes de prensa los que "maquillan" los informes técnicos. Los periodistas creen que esos informes son "palabra de Dios" o "palabra de Ciencia" sin plantearse que estos informes, con pretensiones científicas o técnicas, son uno de los mejores métodos manipuladores que existen. Evidentemente un periodista no tiene elementos para cuestionar un informe técnico. Pero sí está obligado a introducir un despiece en su reportaje en el que señale los siguientes puntos para prevenir al lector: 
Medio ambiente, manipulación política y control mediático del riesgo...

a) Que en España la ley de función pública obliga a los funcionarios (excepto a profesores universitarios acogidos a la libertad de cátedra e investigación) a no revelar directamente sus investigaciones a los medios de comunicación sin el permiso de toda la jerarquía que, normalmente, tiene su cúspide en un cargo político.

b) Que esta estrategia se consolidó en el franquismo y que no se ha modificado en los distintos gobiernos democráticos. También debe advertir que esta forma de actuar tiene su origen en el escaso peso que la ciencia y la técnica han tenido siempre en la historia de España.

c) Debe hacer hincapié en que una de las formas que tiene un ingeniero o científico para escalar puestos en la administración española consiste en elaborar informes que avalen el criterio político imperante.

d) Debe recordarle al lector todos los casos (puede ayudarse de los que aparecen aquí) en los que se demuestra que los comités de expertos de la administración manipularon información y se demostró mucho después.

e) Deben siempre contrastar esos informes con las versiones de profesores universitarios independientes (normalmente son los que no pertenecen a comités o a las jerarquías universitarias) así como con la Academia de Ciencias.

f) Debe siempre pedir opinión a expertos extranjeros de países con una cultura de libertad y de ciencia mayor que la española. Por tanto son, básicamente, países anglosajones.

En el caso del Prestige en el momento de redacción de este artículo -agosto de 2005- se habían publicado 15 informes. Sin embargo, el último (informe no 15) se publicó el 20 de febrero de 2003. Es decir, que al igual que Doñana, en los cuatro primeros meses, mientras el tema fue noticia periodística, se publicaron todos los informes científicos. ¿Se han elaborado más informes entre 2003 y 2005 ? Posiblemente sí pero no los darán a la prensa "para no remover más el tema".

\section{¿CÓMO SON LOS INFORMES?}

Un análisis de los 15 informes emitidos por el CSIC en el caso Prestige nos confirma varias hipótesis:

1) Que sólo se emiten informes cuando el asunto es noticia.

2) Que en este caso (y comparado con los de Doñana) son mucho más técnicos y están pensados para que el periodista (sin formación en química) no sea capaz de interpretarlos sin un "guía" que normalmente será el presidente del comité de expertos.

3) Que posiblemente se redactaron varias versiones de los informes. Una más clara para los políticos y otra para los periodistas. Esta hipótesis está avalada 
en unas declaraciones del entonces presidente de la Xunta, Manuel Fraga, que afirmó que "el fuel vertido tiene algunas complicaciones" (25-11-2002). Pero de los informes (tres en ese momento) no se intuía qué quería decir con eso. Fue el diario El Mundo (29-11-2002: portada) quien lo desveló "El fuel derramado por el Prestige en Galicia es altamente cancerígeno". El diario El Mundo había buscado en otro lado: en los científicos franceses. La noticia publicada por El Mundo usaba un informe del Centre de Documentatation, de Recherche et d' Experimentations sur les pollutions accidentelles des Eaux de Francia (CEDRE). Entre otros datos el informe señalaba que el fuel del Prestige contenía hasta seis hidrocarburos aromáticos clasificados como "posible carcinógeno humano" por la Agencia de Investigación Internacional del Cáncer (IARC). La noticia, evitada en los informes españoles, era importante porque muchos voluntarios recogían el chapapote sin mascarillas antigás necesarias para evitar la inhalación de los gases cancerígenos que desprendía el chapapote.

La publicación, el 29 de noviembre por El Mundo, del informe francés sobre la toxicidad del fuel provocó que los expertos del comité científico tuvieran que publicar un informe "español" para paliar la vergüenza científica internacional. El informe del CSIC fue presentado el viernes 27 de diciembre; es decir, casi un mes después de que El Mundo publicara los resultados del informe francés. Las conclusiones del informe fueron recogidas ese mismo viernes en radio, televisión y diarios digitales y el sábado por toda la prensa.

El Informe del CEDRE publicado por El Mundo el 29 de noviembre favoreció que ese mismo día la organización ecologista Greenpeace afirmara que el Instituto de Investigaciones Químicas y Ambientales de Barcelona, que pertenece al CSIC, les había confirmado la presencia en el vertido de hidrocarburos aromáticos policíclicos (HAP). Pero, obviamente, ningún científico del CSIC puede hacer declaraciones porque se expone a un expediente disciplinario.

El que sí las hizo fue el que en ese momento era el portavoz oficial para este tema, José Luis García Fierro. Dos días después de la publicación del informe francés en la prensa, el lunes dos de diciembre, José Luis García Fierro rebatió esos análisis matizando que los compuestos de fuel derramados por el Prestige "en las condiciones en las que se encuentran no son lesivos para los seres vivos". Y añadió: "No hay que ser alarmistas ni sacar las cosas de su sitio". Sus declaraciones fueron recogidas por todos los medios. Esta desautorización oficial del CSIC a los análisis que la propia institución había elaborado favoreció que un grupo de científicos del CSIC de Vigo criticara a los responsables del organismo por "ocultar información" y "hacer una mala gestión de la crisis "(El Mundo, 12-12-2002)". Estos científicos se expusieron a un expediente disciplinario "muy grave".

Debe matizarse que entre esas dos fechas -del 29 de noviembre y el 29 de diciembre- existe una fecha intermedia -la del 11 de diciembre de 2002- en la que un grupo de 96 científicos de las tres universidades gallegas junto al grupo 
ecologista Greenpeace presentan ${ }^{1}$ un documento en el que entre otras referencias señalaban que "el fuel tiene compuestos orgánicos persistentes de carácter bioacumulativo, en muchos casos posibles carcinógenos humanos". También consideraban que el vertido "producirá efectos a corto y largo plazo sobre el sustrato y la estructura del ecosistema que permanecerán durante generaciones en la cadena trófica". Este comunicado fue publicado por la prensa (El País y El Mundo, 12-122002).

\section{INFORMES COPIADOS: LA VERGÜENZA DE LA CIENCIA ESPAÑOLA}

El domingo 29 de diciembre -justo un mes después de la publicación por El Mundo del informe de toxicidad francés-, el diario El País publicaba en portada el siguiente titular: "EI informe del CSIC sobre toxicidad del fuel copia uno francés anterior" (El País, 29-12-2002). La ciencia española nunca había caído tan bajo desde la época franquista. El editorial de El País señalaba: "Las democracias modernas, incluso las más consolidadas, no son inmunes a la manipulación de sus reglas de funcionamiento, sobre todo si les falta suficiente rodaje democrático a sus responsables de turno" (El País, 29-12-2002: 10).

En páginas interiores el diario El País titulaba: "EI CSIC plagia el informe toxicológico francés". (El País, 29-12-2002). En la entradilla se señalaba:

Cuando se cumple mes y medio de la catástrofe del Prestige, el CSIC publicó el viernes un 'informe sobre la toxicidad de los residuos del petrolero Prestige' que se reduce a un mero resumen de otro elaborado por el instituto francés CEDRE 30 días antes. EI CSIC ha negado rotundamente que su documento sea un resumen o una copia del realizado por sus colegas franceses. No obstante, ambos informes coinciden en el fondo y forma, aunque el francés, pese a ser anterior, sigue siendo más completo y detallado. (El País, 29-12-2002).

\section{DIFERENCIAS Y ANALOGÍAS ENTRE EL INFORME CIENTÍFICO DEL CSIC Y EL DEL CEDRE}

Quien suscribe este artículo ha realizado un análisis de ambos informes que se detallará en los párrafos siguientes. No obstante, debe matizarse que los medios de comunicación también denunciaron las similitudes a partir de sus propias comprobaciones de ambos informes. Es decir, los medios no siempre son cómplices de estas estrategias. Lo que sucede es que no siempre se enteran porque trascienden la capacidad de trabajo de un periodista. En este caso, el diario El País, no sólo colgó ambos informes en su sitio web, sino que publicó un amplio reportaje sobre la comparación (El País, 9-12-2002), parte del cual también se ha usado en este apartado.

\footnotetext{
Realizaron la rueda de prensa a bordo del barco SV Rainbow Warrior, perteneciente a Greenpeace. El buque estaba fondeado en esas fechas en el Puerto de Vigo.
} 
El informe del CSIC aparece sin firmar (no hay científicos que se hagan responsable de él) mientras que el informe del CEDRE aparece firmado por el científico Alain Baert.

El informe realizado por Baert es más minucioso y contiene seis páginas, frente a las cuatro del informe del CSIC.

Como ya se ha mencionado, otra de las diferencias es que el informe del CEDRE se publicó (incluido el diario El Mundo) 30 días antes que el del CSIC.

La similitudes entre ambos informes son tanto relativas a su organización -en bloques muy parecidos- como en los resultados y recomendaciones. No obstante, lo que sorprende es que la redacción es similar.

En el apartado "Medidas preventivas", que en ambos informes aparecen en último lugar, las precauciones a adoptar en caso de estar en contacto con el fuel se enumeran en el mismo orden aunque con una sutil deferencia de palabras. "No autorizar la actividad a quienes padezcan patologías respiratorias, cardiacas, hepáticas...", señala el informe de Baert. "No autorizar la participación en tareas de limpieza a personas que sufran patologías respiratorias, cardiacas, hepática...", aparece en el informe del CSIC.

"Tener siempre a disposición el material necesario para descontaminar la piel con aceite (cualquier aceite de mesa) y después aclarar con agua y jabón", se lee en el informe del CEDRE. "Disponer de métodos fáciles de limpieza de la piel (aceite de mesa para disolver el petróleo, agua y jabón)", se indica en el informe del CSIC.

Todas las recomendaciones están escritas en el mismo orden y sólo hay una diferencia, por omisión, ya que el informe del CSIC no alude a la propuesta de "habilitar vestuarios independientes para ponerse y quitarse el equipo de trabajo", que sí recoge el texto del informe francés.

El informe del CEDRE hace referencia, al final de su exposición, a "una serie de medidas complementarias, como la definición del estatuto del voluntariado y un seguimiento médico de los participantes". El informe técnico del CSIC no dice nada del estatuto del voluntariado ni de los participantes en general. Sólo señala que "sería deseable llevar a cabo un estudio epidemiológico, especialmente entre los marineros y pescadores que trabajan en las tareas de limpieza".

Ambos informes concluyen con referencias a las personas que trabajan con aves. "Con frecuencia, las personas que recogen aves no están bien protegidas", escribe Baert. Y el informe del CSIC sostiene: "Los cuidadores de aves tendrán que llevar guantes y trabajar en salas bien ventiladas".

En el segundo bloque, el dedicado en ambos informes a los efectos y las vías de exposición al fuel, el informe francés explica de manera más extensa cómo se distribuyen los componentes tóxicos de la piel a los órganos con más grasa y a 
los pulmones, fundamentalmente. También describe las irritaciones que pueden surgir en la piel y ojos debido a que la vía cutánea es la vía de exposición más amenazada. Todo esto en el informe del CEDRE se extiende a casi una página. Sin embargo, en el informe del CSIC se resume en: "El contracto directo con el petróleo o sus vapores causa irritación y/o picores en la piel y enrojecimiento en los ojos". La simplificación, para evitar que los medios publicaran el peligro potencial, produce, simplemente, vergüenza.

El tercer bloque lo dedican ambos informes a la toxicidad de los compuestos más peligrosos del vertido por su potencialidad cancerígena: los hidrocarburos aromático policíclicos (HAP). Sin embargo, el informe español sólo intenta quitar importancia al peligro del vertido mientras que el francés remite continuamente a estudios publicados sobre su toxicidad. Así, el informe del CSIC señala que: "Los HAP se encuentran en concentraciones que no suponen un peligro de intoxicación agudo para la salud, sino crónico. En este contexto, riesgos como la formación de cánceres se calculan a partir de una exposición permanente o a muy largo plazo". Y, después, pone como ejemplo el riesgo de un fumador. Sin embargo en el informe francés se señala que "el benzopireno, ligado al humo del tabaco, es el HAP más estudiados y los peligros de los HAP pueden deducirse de los estudios de este compuesto". Debe aclarase que los estudios sobre este compuesto confirman un peligro de tal magnitud que es lo que avala que ni siquiera se pueda fumar en un aeropuerto por los peligros para el fumador pasivo.

\section{EL PLAGIO NO MENCIONA LA FUENTE ORIGINAL}

A pesar de todas las coincidencias, la guinda del proceso de manipulación y plagio del informe del CSIC se obtiene al comprobar que el informe del CSIC ni siquiera cita el del CEDRE ni, por supuesto, a su autor, Alain Baert. Las reglas sucias del plagio sucio sostienen que debe omitirse la fuente de la que se plagia y referenciar otras para que no pueda descubrirse la pista. $Y$ eso hizo el comité de expertos del CSIC: citó fuentes como la Agencia Internacional de Investigación sobre el Cáncer y la EPA (Agencia de Protección Medioambiental) estadounidense. La única vez que se nombra el CEDRE en todo el informe es cuando aparece relacionado con el del caso del petrolero Erika -y es aquí cuando cita la web del CEDRE-. Pero, repito, en ningún momento se menciona el estudio del CEDRE sobre el Prestige con muestras que el propio instituto francés recogió unos días después de la catástrofe.

EI CSIC reaccionó indignado ante la noticia publicada por El País. Sobre todo porque el sitio web de este diario insertó un enlace a los dos informes completos, de forma que todo interesado pudo comprobar las similitudes y diferencias entre ambos informes así como las omisiones. Como dicen en las facultades de Periodismo acusar con la verdad sienta muy mal al poder, pero acusar con la verdad a través de pruebas claras implica que la reacción del poder contra el periodista es terrible. La noticia de El País se publicó el domingo 29 y el lunes 30 reaccionó el 
CSIC. Es fácil imaginarse la crisis que se desató ese día. Y aquí hay otro dato curioso. Mientras que el presidente del comité de expertos del CSIC sobre el Prestige era Emilio Lora Tamayo y, por tanto, responsable del informe, quien salió a lavar la cara del CSIC por el informe del comité de expertos no fue Lora Tamayo, sino el presidente del CSIC en principio ignorado por el PP, Rolf Tarrach. Tarrach reconoce que obviar la cita del CEDRE fue "un error involuntario por el que pide disculpas" (El País, 31-12-2002).

La estrategia mediática estaba clara: Tarrach ya era un cadáver político, mientras que si salía Lora Tamayo a dar las explicaciones, perdería credibilidad ante la opinión pública para futuros informes. También resulta curioso que mientras la noticia del domingo 29 aparecía firmada por la periodista Patricia Ortega Dolz, la del martes 31 de diciembre que titula: "EI CSIC niega haber copiado un informe francés, aunque reconoce que usó sus recomendaciones", aparece sin firmar².

El 31 de diciembre de 2002 y el uno de enero de 2003 fueron días festivos en el CSIC, pero su maquinaria de prensa siguió diseñando estrategias mientras se comían las uvas de fin de año. Se trataba ahora de sacar otro informe con una valor muy positivo que paliara, no sólo el hecho de la toxicidad del fuel, sino que eclipsara el debate sobre el informe copiado. Lo mejor: publicar otro informe. Así, el mismo día dos de enero -el primero tras las vacaciones- se difundió otro informe.

Llamo la atención al lector sobre la asombrosa rapidez, en principio tan contraria a la ciencia verdadera. Y es que en apenas seis días, en plenas Navidades, y con las fiestas de fin de año en medio, el CSIC publica otro informe el dos de enero. Las conclusiones de ese informe abrieron informativos del día dos de enero. El día tres el diario El País titulaba: "El comité científico del CSIC asegura que no se abrirán nuevas grietas en el Prestige," (El País, 3-01-2003). El Mundo, Abc, El Periódico de Catalunya y La Vanguardia también titularon por ese aspecto, que fue también el de la Agencia Efe, por lo que, previsiblemente, ése fue el enfoque de todos los periódicos locales.

\section{EL MALESTAR DE LOS CIENTíFICOS ESPAÑOLES}

Este informe fue la gota que colmó la paciencia de los científicos. Primero por la inusitada rapidez y, segundo, porque al igual que lo de que el fuel se solidificaría en el fondo -en esa época ya llevaba más de un mes hundido y aún seguía saliendo fuel- el enfoque de ese informe parecía más una opinión que un resultado científico. Mi hipótesis en este caso es que los informes estaban redactados desde el gabinete de prensa con datos científicos. Porque... ¿qué quiere decir que no se

\footnotetext{
${ }^{2}$ No obstante, este último dato -que cuando intenté su comprobación en El País nadie recordó su causa-, puede ser debido simplemente a que ese día 31 de diciembre se prefirió usar la información proveniente de la Agencia Efe. Aunque tampoco se menciona esta fuente en la información cuando El País sí suele hacerlo.
} 
Medio ambiente, manipulación política y control mediático del riesgo...

abrirán nuevas grietas? La ciencia predice que el casco de hierro se oxidará en el agua. Por tanto, no sólo se formarán grietas: todo el barco será una grieta.

De hecho, al final de ese mes -el 27 de enero- tuvo que publicar otro informe en que se señalaba que el casco se rompería. El diario El Mundo (28-01-2002) tituló "Un informe advierte de que el caso del Prestige se romperá". Como subtítulo indicaba: "El Comité Científico Asesor asegura que la corrosión por óxido hará salir el fuel a la superficie dentro de 23 años". El diario El País (28-01-2002) tituló: "La corrosión romperá los tanques de fuel del Prestige en un periodo de entre 23 y 40 años".

Pero antes de ese 27 de enero y después de las Navidades habrían de pasar cosas muy importantes. Y es que tanto la emisión del informe de la ausencia de grietas como, sobre todo, el asunto del plagio del informe francés habían soliviantado, por primera vez en la democracia, a la ciencia española.

No obstante, debe aclararse que mucho antes ya había comenzado este movimiento de científicos en contra de los informes del CSIC. Así, como ya se ha mencionado, el 11 de diciembre de 2002 un grupo de 96 científicos de las tres universidades gallegas junto a la organización ecologista Greenpeace presentaron un documento a la prensa en el que desmintieron algunos postulados que hasta ese momento el CSIC consideraba como científicos. En el texto remitido por la Agencia Efe (y publicado entre otros por El País y El Mundo el 12-12-2002) se señala que:

Los representantes de las universidades gallegas denunciaron que las investigaciones que realizaron tras el accidente del Prestige fueron ignoradas por las administraciones implicadas, que no solicitaron ni su colaboración ni su asesoramiento. Además lamentaron la falta de información proporcionada desde el Gobierno español mientras trabajaban con datos facilitados por organismos portugueses y franceses. (...) Por su parte, varios trabajadores del Centro Superior de Investigaciones Científicas (CSIC) de Vigo criticaron ayer a los responsables del organismo por 'ocultar información' y 'hacer una mala gestión de la crisis' (El Mundo, 12-12-2002).

\section{LA REVISTA SCIENCE CERTIFICA LA POLITIZACIÓN DE LA CIENCIA ESPAÑOLA}

El caso Prestige continúa en el tiempo. En la prensa lo hace con fuerza hasta que España entra en la Guerra de Irak y, sobre todo, su presencia en los medios disminuye después del atentado en Madrid (marzo 2004) y el cambio de gobierno tras las elecciones del 14 de marzo de 2004. Es un caso claro de catástrofe ecológica que se usa políticamente por todos los grupos parlamentarios. No obstante, desde el punto de vista que nos interesa en este artículo, el de la ciencia como elemento de manipulación y sus consecuencias, podemos afirmar que el caso Prestige tiene su culminación el viernes 24 de enero de 2003 cuando prestigiosa la revista Science ${ }^{3}$, editada por la Asociación Americana para el Avance de la Ciencia, publica un manifiesto firmado por 422 científicos pertenecientes a 32 
universidades, el CSIC y el Instituto Español de Oceanografía. En el manifiesto se señala que frente a las declaraciones del gobierno sosteniendo que la decisión de alejar el Prestige de la costa se hicieron "siguiendo criterios técnicos", los científicos españoles aclaran que "las decisiones tomadas no obedecen a ningún criterio científico, y el problema fundamental reside precisamente en el hecho de que el Ejecutivo no consultó con los expertos investigadores".

La base de la argumentación de los científicos españoles era simple: si desde hace 25 años se sabe que hay una corriente dirigida hacia el norte ¿por qué se llevó el barco hacia el sur? Según los científicos firmantes de cartas y manifiestos, tanto el traslado al sur como los cambios de rumbo ampliaron las consecuencias de la catástrofe. Los científicos españoles se quejaban "del desaprovechamiento de un potencial humano de valor inestimable; esto es, los investigadores de Ciencias del Mar".

Debe matizarse que esta crítica se hacía porque según aseguró en el Congreso de los Diputados el vicepresidente primero del Gobierno de esa época, Mariano Rajoy, la decisión clave de alejar el barco se tomó siguiendo las opiniones de 17 técnicos entre los que, según Rajoy, había ingenieros navales de la empresa IZAR, capitanes de la Marina Mercante, profesores de la Escuela Superior de la Marina Civil de A Coruña y de la Escuela de Ingeniería Naval de Ferrol.

No obstante, jamás el gobierno dio los nombres de esos supuestos expertos. De manera que existen aquí dos hipótesis. Una es que jamás hubiese consultado a esos expertos y otra que sí lo hiciera y que, tal vez, ante la metedura de pata de los ingenieros españoles y presionados por los colegios profesionales de ingenieros, muy poderosos en la historia de España, el Gobierno no diera nombres para que no se desprestigiara aún más la profesión.

Los científicos también se quejaban en Science de que una vez que se derramó el fuel hubo una escasa coordinación de las autoridades españolas así como de un "uso poco eficaz de las instituciones científicas, recursos y conocimiento". Por último demandaban al gobierno "la mejora de mecanismos y logística para las consultas científicas y técnicas"; es decir, que se hicieran las cosas como en los países con tradición científica y terminaban su carta con que con la actuación de España en el caso Prestige "se había dañado la imagen de las ciencias marinas y atmosféricas españolas".

La carta dejaba traslucir que los científicos españoles estaban verdaderamente indignados. De hecho, los decanos de Biología reunidos esos días en Málaga firmaron un escrito en que se indicaba: "Las actuaciones realizadas por las administraciones difícilmente se pueden entender desde un punto de vista científico". Algunas universidades, además de organizarse para enviar voluntarios a limpiar las costas gallegas, emitieron comunicados de protesta por el comportamiento "no

3 Science. Vol. 299. (24-1-2003: 511) 
Medio ambiente, manipulación política y control mediático del riesgo...

científico del gobierno". El presidente de la Conferencia de Rectores de la época, Ignacio Berdugo, sostuvo que el gobierno podía haber "consultado bastante más a los investigadores" y recordó que las universidades españolas tienen el $77 \%$ de la investigación que se hace en este país.

Alberto Otero, director del Instituto de Investigaciones Marinas de Vigo, perteneciente al CSIC, llegó a declarar en El País: "Estoy hasta las narices de lo que estoy leyendo. Tenemos que aprender de este error monumental. Hay que saber a quien tenemos que llamar en el caso de catástrofes parecidas, qué barcos enviar y cómo movilizar a los medios. Me avergüenza que un país como España tenga que depender de los pronósticos del viento y las corrientes para saber dónde está una mancha" (El País, 23-01-2003).

La carta de Science no era una simple carta. La revista dio todo su amparo a los científicos españoles y en la sección "News of the week" y bajo el título "Los científicos españoles muestran su cólera por cómo se ha dirigido el vertido de petróleo", dos comentaristas ${ }^{4}$ hacían su apreciación del asunto.

Desde que el petrolero Prestige se hundiera en las costas ibéricas, el gobierno español ha sido criticado por cómo ha manejado la crisis. Ahora, los científicos unen sus voces, en masa, como forma de protesta. En la carta de la pagina 511, 422 científicos marinos y atmosféricos acusan al gobierno de ignorar a la comunidad científica durante todo este tiempo (Science, p. 490).

No obstante, lo peor para la imagen de la ciencia española fue la confirmación desde Science de la falta de libertad de expresión que tienen los científicos españoles:

El gobierno ha trabajado más para defenderse su política que para solucionar la crisis, sostiene uno de los firmantes de la carta, el ecólogo marino Antonio Bode del Instituto Español de Oceanografía en A Coruña. Según Bode, los científicos estatales, incluidos los que pertenecen a su instituto, recibieron un correo electrónico general, con fecha 15 de diciembre, en el que se les dijo que no podían hablar con la prensa sobre el Prestige. Él y muchos otros han desafiado esa orden con esta carta a Science. (...) Bodes asegura que el gobierno no tiene confianza en sus investigadores (Science, p. 490).

En realidad no desafiaron la orden, porque de haberlo hecho hubieran puesto en peligro sus puestos de trabajo como funcionarios públicos. Lo que hicieron fue enviar una carta "científica" pero no a un medio de comunicación, sino a una revista científica de prestigio (una de las más importantes del mundo) de modo que ante un juez eso no es delito. Que los medios de comunicación se hicieran eco de la

${ }^{4}$ Los comentaristas fueron John Bohannon y Xavier Bosh. 
carta no "era culpa de ellos". Iba firmada, además, por muchos científicos para que el delito no recayera en uno solo.

Pero el problema es la imagen de España en la comunidad científica internacional. Con esa frase de que "el gobierno prohibió a los científicos hablar con la prensa" publicada en Science parece que da una descripción de una dictadura en la que no existe libertad de expresión. Este e-mail fue enviado con la tecnología del siglo XXI, pero su contenido recuerda el discurso de inauguración del CSIC en 1940. José Ibáñez, el primer ministro de Educación de Franco y primer presidente del CSIC dijo en aquel entonces, recién terminada la Guerra Civil:

\begin{abstract}
Queremos una ciencia católica, esto es una ciencia que por sometida a la razón, suprema del universo, por armonizada con la fe, en la luz verdadera que ilumina a todo hombre que viene a este mundo, alcance su más pura nota universal. Liquidamos, por tanto, en esta hora, todas las herejías científicas que secaron y agostaron los cauces de nuestra genialidad nacional y nos sumieron en la atonía y la decadencia. (...). Gracias al apoyo de nuestro egregio Caudillo -que vive en entrega plena y absoluta al servicio de la Patria- el Consejo [CSIC] es hoy un poderoso instrumento puesto al servicio de los valores espirituales del estado (Memoria CSIC, 1942: 15-16) . $^{5}$
\end{abstract}

Como es sabido, tras discursos como éste, la mayoría de los científicos españoles de la II República tuvieron que exiliarse. Ese exilio de científicos como Blas Cabrera, Rey Pastor, Miguel Catalán contribuyó a dar en el extranjero una imagen de que España era un país de espaldas a la ciencia (Elías, 2001a). Lo peor no es la imagen, sino que en muchos aspectos como el control político del CSIC, ésa era la realidad en la que vivía en 2002 la ciencia española (Elías, 2003: 263). En 2005, con el gobierno socialista en el poder, aún no se ha modificado esa relación.

\title{
DIMISIÓN DEL PRESIDENTE DEL CSIC
}

En el CSIC iba creciendo la opinión contraria a la manipulación informativa. Ya se ha mencionado el escrito de los trabajadores del CSIC de Vigo en el que se señalaba que "entre todos los escenarios posibles el gobierno ha optado por el peor". También se quejaban de la "contaminación informativa y la desinformación practicadas por los gobiernos central y autonómico sobre este asunto". La espiral de crítica arreciaba desde dentro del CSIC. El día 22 de enero el claustro del Instituto de Ciencias de Materiales de Madrid, también dependiente del CSIC, acusaba al Gobierno de tratar "de reducir la ciencia española a la nulidad como demuestra la deplorable actuación del Ejecutivo ante el hundimiento del Prestige".

\footnotetext{
${ }^{5}$ De esta memoria sólo existen dos ejemplares. Uno en el Instituto de Filosofía del CSIC y otro en la biblioteca del Museo Nacional de Ciencias Naturales.
} 
Los científicos se reconocían "desmoralizados" por la imagen que se estaba transmitiendo. El comunicado también fue publicado en El País (23-01-2003).

El viernes 24 de enero de 2003 se publica el manifiesto en Science. La comunidad científica internacional conoce de primera mano el acoso, el maltrato y el desprecio al que, nuevamente, está sometida la comunidad científica española. El tufillo a lo que había sucedido taras la Guerra Civil con el exilio de los mejores científicos españoles, por no comulgar con las ideas políticas, estaba latente. El presidente del CSIC, Rolf Tarrach, no aguantó más y ese mismo día presentó la dimisión. Tarrach es un buen científico, pero pertenecía a una universidad -la Autónoma de Barcelona- y no concebía esa forma de hacer las cosas en el CSIC. Él quería más libertad pero el sistema no le dejó (Elías, 2003, 265). También creo, y esto es una opinión personal, que se dejó arrastrar excesivamente por el responsable de prensa de ese momento.

La noticia de la dimisión apareció en toda la prensa nacional el día siguiente a la publicación de la carta en Science. El diario $A b c$ fue quien más espacio le dedicó. Abría su sección de sociedad con este tema y titulaba "Rolf Tarrach alertó en su carta de dimisión de la fuga de investigadores del CSIC a la universidad", (Abc, 25-1-2003). Debe mencionarse que Tarrach rechazaba que su dimisión tuviera que ver con el Prestige sino que era por "la falta de autonomía de gestión y la rigidez administrativa que atenazan al CSIC". Pero era obvio que la fecha elegida para su dimisión -justo el día de la publicación del manifiesto en Science- era muy significativa de lo que realmente pensaba. Él no quería que los políticos $-y$ periodistas del gabinete de prensa- utilizaran su gran prestigio como investigador para avalar decisiones científicas erróneas. Y Tarrach dimitió. Como ya se ha mencionado Lora Tamayo fue quien lo sustituyó al frente del CSIC durante todo el periodo que el PP estuvo en el poder.

\section{CONCLUSIÓN}

Como conclusión del caso Prestige podemos indicar que la manipulación informativa fue menos sutil que en Doñana (Elías, 2001) y eso provocó que la comunidad científica se volviera en contra del gobierno. También hubo un apoyo expreso de todos los medios de comunicación del grupo PRISA (El País, Cadena Ser, Canal Plus, etc) hacia todos los sectores críticos con la gestión del Prestige. PSISA fue muy crítica tanto con el gobierno central como con el de la Xunta de Galicia, ambos del PP. Sin embargo, esto no está tan claro en el caso Doñana, en el que la Junta de Andalucía tuvo gran parte de culpa al no inspeccionar debidamente las actuaciones de la empresa Bolidem. El grupo PRISA arremete más contra el gobierno central de la época -que era del PP- que contra la Junta de Andalucía -que era del PSOE- (Elías, 2001).

En el caso del Prestige arremete contra ambos por igual. El diario El Mundo sigue una línea muy crítica tanto en el caso Doñana -en el que critica tanto al PSOE de la Junta andaluza como al PP de Madrid- como en el caso del Prestige. 
No olvidemos que es El Mundo quien publica por primera vez las conclusiones sobre los efectos tóxicos del fuel vertido en la costa gallega. El diario $A b c$ es más suave -tanto en sus titulares como en la importancia que le otorga al tema- en ambas catástrofes, pero sobre todo en el caso del Prestige.

Respecto al uso de los científicos como fuentes, en el caso Doñana, los periodistas confiaron más en ellos y, sobre todo, en el CSIC. En el Prestige fueron más cautos y buscaron referencias en otros países y con científicos al margen del sistema oficial. También tuvieron más tiempo para hacerlo: mientras que el comité científico de Doñana se constituyó sólo unos días después de la catástrofe, el del Prestige lo hizo 26 días después con lo que los periodistas tuvieron tiempo de buscar científicos fuera del comité. No obstante, debe matizarse que mientras que en el caso Prestige varios países tenían acceso a los datos -básicamente los que podían sentirse perjudicados directamente como Francia y Portugal- en Doñana existía un control absoluto por parte de España, pues se acordonó la zona afectada y los científicos que no estuvieran autorizados por el gobierno no tenían acceso a la zona contaminada. Pero en el Prestige era imposible ponerle barreras al mar. En ningún caso (ni en Doñana ni en el Prestige) se cuestionó en los medios de comunicación el modelo científico español en el que el CSIC tiene una alta vinculación política.

\section{REFERENCIAS:}

BAUER, Martin W., GASKELL, George. (edits.) (200): Biotechnology: the making a global controversy. Cambridge University Press.

BUCCHI, Massiminiano (1998): Science and the Media. Routledge.

CSIC. (1942). Memoria de actividades de 1940. Madrid.

DE PABLOS, José Manuel y ELIAS, Carlos (2003): "CSIC: chapapote de la ciencia española o cómo se manipula la información en catástrofes ecológicas" en Revista Latina de Comunicación Social, ㄲo 53.

ELIAS, Carlos (2001): "Periodismo especializado en medio ambiente: el caso Doñana como paradigma de manipulación informativa", en Ámbitos, Revista Internacional de Comunicación, ㄲo 6 pp. 297-303.

ELIAS, Carlos (2001a): "Influencia de la Historia de España (siglos XIX y XX) en el periodismo especializado en ciencia" en Revista Latina de Comunicación Social, oo 40.

ELIAS, Carlos (2003): La ciencia a través del periodismo. Nivola.

ELIAS, Carlos (2003a): "Adaptación de la metodología de observación participante al estudio de los gabinetes de prensa como fuentes periodísticas" en Revista de Metodología de las Ciencias Sociales "Empiria”, pp. 145-159. 
190 Medio ambiente, manipulación política y control mediático del riesgo...

GIERYN, Thomas F. (1999): Cultural Boundaries of Science: Credibility on the line. University of Chicago Press.

JASANOFF, Sheila, MARTELLO, Marybeth (edits.). (2004): Earthly Politics. Local and Global in Environmental Governance. The MIT Press. USA.

JASANOFF, Sheila (1990): The Fifth Branch: Science Adviser as Policy Makers. Harvard University Press.

KENNEDY, Robert Jr. (2005): Crimes against Nature. Penguin. London.

LITFIN, Karen (1994): Ozone Discourses: Science and Politics in Global Environmental Cooperation. Columbia University Press.

LOFSTEDT, Ragnar, FREWER, Lynn (edits.) (2004): Risk \& Modern Society. Earthscan.

SHOLZ, Astrid (2004): "Merchants of Diversity: Scientists as Traffickers of Plants and Institutions", in Local and Global in Environmental Governance The MIT Press.

(Recibido el 15-12-05, aceptado el 2-02-06) 